\title{
The Effects of Controlled Language Processing on Listening Comprehension and Recall
}

\author{
Mohsen Jannejad ${ }^{1}$, Hossein Shokouhi ${ }^{1} \&$ Somayeh Biparva Haghighi ${ }^{1}$ \\ ${ }^{1}$ English Language Department, Shahid Chamran University, Ahvaz, Iran \\ Correspondence: Somayeh Biparva Haghighi, English Language Dept. Shahid Chamran University, Ahvaz, Iran. \\ Tel: 98-611-3334458. E-mail: sbh18370@yahoo.com
}

Received: April 22, 2012 Accepted: May 18, 2012 Online Published: July 31, 2012

doi:10.5539/elt.v5n9p155 URL: http://dx.doi.org/10.5539/elt.v5n9p155

\begin{abstract}
This study seeks to determine the possible interactions between listening proficiency and the state of strategic self-awareness; second, and more importantly, to investigate the effects of learned strategies on listening comprehension and recall; and finally to describe the most common real-time listening comprehension problems faced by EFL learners and to compare the differences between learners with different listening abilities. After ten training sessions, an assessment was made to see whether or not well-learned strategies could provide students with ample opportunity to practice the comprehension and recall processes. The analyses of the data revealed the causes of ineffective low-level processing and provided insights to solve the problems of parsing. Moreover, the study reveals that explicit instruction of cognitive and metacognitive strategies is needed if a syllabus wishes to help learners improve their listening comprehension and become more-proficient at directing their own learning and development as L2 listeners.
\end{abstract}

Keywords: language processing system, listening strategies, metacognitive-knowledge

\section{Introduction}

Listening is the skill with which many learners feel the most uncomfortable. Arnold (2000, p. 774) comments on how listening induces a noticeable load on learners, because of the pressure it places on them to process input rapidly. In many ways, it is unsurprising that learners perceive listening as difficult. Buck (2001:29) emphasizes the complexity of the listening process and maintains that listeners must use a wider variety of knowledge sources, linguistic and non-linguistic, to interpret incoming data. Recently, Foreign Language Learning (FLL) and Second Language Acquisition (SLA) research has witnessed a preponderance of studies that examine language acquisition under cognitive and information processing frameworks (Leow, 1997; Doughty and Williams, 1998; Field, 2003; Radwan, 2005; Graham, 2006; Ali, 2007).

To check the reliability of the processing framework, this study has mainly focused on ways to explore the role of controlled language processes (i.e., awareness, cognitive and metacognitive strategies) in listening tasks. This study discusses several issues in language learning strategy research that affected a sample group of Iranian English learners. These issues include: identification procedures of learning strategies, the effects of learner characteristics on strategy use, explicit and integrated strategy instruction, and application of strategies to the required tasks. To accomplish these issues, the research sought to explore the relationship between preferred language strategies, proficiency, and self-efficacy believes.

\subsection{Research Questions}

The present study intended to shed light over the effects of learned attention as a controlled language process on listening comprehension and recall in EFL learners during listening tasks. It was attempted to trace the role and allocation of attention in the control of memory with the aim of enhancing the encoding, storing, and retrieving of information. The study, therefore, sought to answer the following questions:

1) How can listening proficiency level determine students' state of consciousness?

2) How can selective attention and learned strategies influence what is comprehended and stored in the process of listening?

3) What are the problems in information retrieval? 


\subsection{Objectives and Significance of the Study}

In his review of theoretical perspectives on listening, Lynch (1998) calls for further examination of listeners' on-line procedures for monitoring and remedying gaps in comprehension. It is believed that students who do not seem to realize that a learning task is not progressing well can be taught to monitor their comprehension, production, or recall so that they can identify difficulties and select learning strategies to address the difficulties (Chamot, Barnhardt, El-Dinary, \& Robbins, 1999).

Learning strategies are the conscious thoughts and actions that learners take in order to achieve a learning goal. Strategic learners have metacognitive knowledge about their own thinking and learning approaches, a good understanding of what a task entails, and the ability to orchestrate the strategies that best meet both the task demands and their own learning strengths. Many language instructors are aware that individual learner differences more or less contribute to the success of language learning. This paper discusses several issues in language learning strategy research that affected a sample group of Iranian English learners.

According to Larsen-Freeman (2001), a variety of learner differences can be grouped into two main categories: (1) conceptualization, indicating how they conceptualize second-language acquisition (e.g., attitude and beliefs); and (2) actions, indicating what they do (e.g., learning strategies). Extensive research (Ellis, 1985; Call. 1985; Wenden, 1999; Brown, 2000) has identified the learning strategies used by students of a variety of second and foreign languages and a somewhat smaller body of research (Leow, 1997; Goh, 2000; Radwan, 2005) has documented the effectiveness of helping less successful language students improve their performance through learning strategy instruction.

\subsection{Information Processing System}

The acts of comprehending and producing language are performed within the constraints of the information processing system. This system consists of three structural components- sensory memory, working memory, and permanent memory- along with a set of controlled processes that govern the flow of information within the system (Carroll, 1994). When information is temporarily stored in initial memories (sensory and short-term), activities such as scanning, searching, and comparing may relate it to other information in long-term storage, resulting in comprehension.

According to Carroll's (1994, p. 49) model of mental functioning, environmental information is successively encoded, stored, and retrieved by a set of distinct mental structures. As shown in Figure 1 below, the model consists of three mental structures and a set of processes that move information from one structure to another.

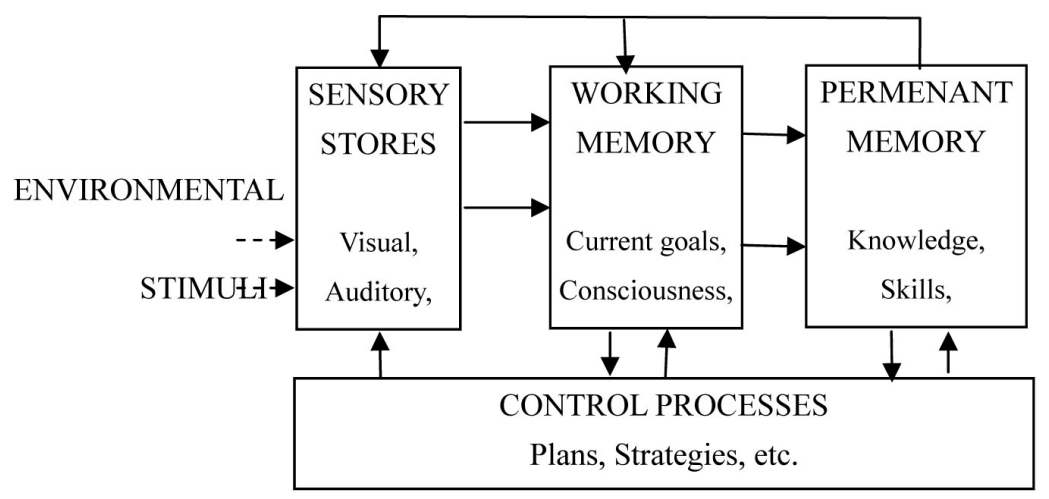

Figure 1. A general model of information processing (Carroll, 1994, p. 49)

As Carroll (1994, p. 50) points out, at the first step in the information processing sequence, the sensory stores represent information in a literal, unanalyzed form. Most of the information in these stores disappears very rapidly because it is not germane to the current goals. But the processes of taking in new information, identifying it, and choosing whether or not to process it more extensively, though rapid, take a measurable amount of time. The sensory stores perform the invaluable function of preserving this information long enough for more extensive processing to be initiated. Concurring with Carroll, Robinson's (1995, p. 322) study on short-term memory constraints approves that attentional resources are limited and these limitations play an essential role in 
L2 speech processing, because its mechanisms are only partially automatic and require conscious controlled attention.

\subsection{Automatic and Controlled Processes}

Controlled processing and automatic processing are identified to be the two principal processing modes: a controlled process "utilizes a temporary sequence of nodes activated under the control of and through attention by the subject". An automatic process is a "sequence of nodes that nearly always becomes active in response to a particular input configuration" and is "activated without the necessity of active control or attention by the subject" (Shiffrin and Schneider, 1977, p. 155-156).

Automatic processes require sufficient training to develop, since they depend upon a relatively permanent set of node associations. McLaughlin, Rossman, and McLeod (1983, p. 144) note that most automatic processing occurs incidentally, in normal communication activities, while most controlled processing occurs in performing new language skills which require a high degree of focal attention. They note that the development of the skills necessary to deal with complex tasks such as language processing "involves building up a set of well-learned, automatic processes so that controlled processes will be freed up for new tasks". Automatic processing is critical to comprehension because too much controlled processing may lead to overload and breakdown.

\subsection{Listening Strategies}

Learning strategies occupy an important position; these have been defined by Cohen $(1998$, p. 4) as an "action taken to enhance the learning or use of a second or foreign language, through the storage, retention, recall, and application of information about that language". Field describes these strategies as 'strictly compensatory' (1998, p. 117), used to make up for learners' imperfect knowledge of the L2 syntax and vocabulary (2000, p. 189).

In 2000, Goh appraises the framework for listening proposed by Anderson (1995). This framework presents listening as a three-stage process, beginning with perceptual processing. Here attention is focused on the text and phonemes are segmented from the speech stream. In the second stage, parsing, meaningful mental representations are formed from words. In the last phase, utilization, information gathered in the previous two phases is related to existing knowledge in the form of schemata. Goh $(2000$, p. 57) claims that her learners reported 10 listening problems which related to all three phases of listening. One difficulty involved was 'understanding the words but not the intended message' (p. 62) but over half of the problems were concerned with word recognition and attention failure during perceptual processing. Lower-ability listeners reported more problems with low-level processing such as speech recognition.

\subsection{Research Hypotheses}

These issues include: identification procedures of learning strategies, terminology and classification of strategies, the effects of learner characteristics on strategy use, explicit and integrated strategy instruction, language of instruction, and application of strategies to the required tasks. To accomplish these issues, the research seeks to explore the relationship between preferred language strategies, proficiency, and self-efficacy awareness. Responding to the call for more replication of strategy research and for research in different cultural contexts, this research was conducted at Shahid Chamran University of Ahvaz on 70 students of English Translation between 2008 and 2009. In reference to the above research questions, this study hypothesizes that:

Hypothesis 1: Subjects' proficiency levels determine their strategic self-awareness and consequently affect their cognitive and metacognitive strategy use.

Hypothesis 2: Well-learned strategies will provide students with ample opportunity to practice the comprehension and recall processes.

Hypothesis 3: Some real-time listening comprehension problems can be identified and prioritized for teaching purposes.

\section{Method}

To diagnose the realization of these objectives, this section focuses on participants and settings, materials and procedures.

\subsection{Participants and Settings}

The study was conducted on 70 English students, two junior EFL Oral Translation classes. One of the classes was treated as the control group and the other as the experimental. The researcher grouped and ranked the students according to the TOEFL test which was administered to determine the listening proficiency of the 
students. According to Dreyer and Nel (2003, p. 254), those students who obtained percentages below 55\% were categorized as less-proficient whereas the students who obtained percentages above $55 \%$ were categorized as more-proficient. In the control group, 16 students obtained scores below 55\% and 19 above 55\%; for the experimental group, 15 students were considered as less proficient and 20 students as more proficient.

\subsection{Materials and Procedures}

Generally, four instruments were utilized for data collection purposes in the study. These included a pre-instruction assessment, Strategy Inventory for Language Learning (SILL) self-report questionnaire, training sessions and think-aloud protocols, and post-instruction assessment. Each of these instruments will be discussed below.

The listening pre-test required students to listen to a number of authentic texts recorded from VOA news program and to verify comprehension by checking the correct choice and recall by answering open-ended questions. The pre-test was administered before the strategy instruction began. The listening component appraised a range of listening skills, such as listening for gist, listening for details and making inferences.

The self-report questionnaire employed in this study was an adapted version of Strategy Inventory for Language Learning (SILL), originally devised by Oxford and Burry-Stock (1995), used to collect and analyze information from the learners. For the aim of this study, the researcher modified the number and the content of the SILL questions to apprehend the learners' overall controlled language processing statuses.

Ten training sessions were conducted on the experimental group to alert the subjects: (a) to identify the listening goal and to decide whether to obtain specific information or the gist of the message, (b) to determine the major facts about a message, such as topic, text type, setting, (c) to outline predictable sequences in which information may be presented: who-what-when-where, (d) identify key words and phrases to listen for (e) to compensate the missing parts by drawing inferences, (f) to monitor their comprehension and the effectiveness of the selected strategies.

Twelve weeks later, as the experimenter assured that the students had been aware of and practiced how to monitor and remedy the gaps in listening comprehension and recall, the post-test session was held in which the students sat for the final listening test in which they were to listen to authentic texts just parallel to those presented to them in the pre-test session to verify comprehension and recall through multiple-choice questions and free recall test successively. The administration of this phase took one class period. The results were compared with those obtained from the pre-tests and analyzed for further introspection.

\section{Results}

At this time, the results of each phase of study, including pre-instruction assessment, SILL questionnaire, think-aloud protocols, and post-instruction assessment are presented successively.

\subsection{Pre-instruction Assessment}

The listening pre-test required subjects to listen to a number of authentic texts recorded from VOA news program and to verify comprehension by checking the correct choice and recall by answering open-ended questions. As Chun and Payne (2004, p. 499) suggest, pre-test measures of learners' listening aptitude would enable a more "fine-grained analysis" of individual learner's behavior patterns and make it possible to "rule out any pre-existing differences" among subjects and groups. Table 1 below summarizes the descriptive analysis of the mean pre-test scores of the participants, which are $16.12(\mathrm{SD}=0.30)$ and $15.95(\mathrm{SD}=0.24)$ for the experimental and control group, respectively.

Table 1. Descriptive statistics of the pre-test scores of experimental and control groups

\begin{tabular}{lllll}
\hline Groups & N & Mean & Std. Deviation & Std. Error Mean \\
\hline Experimental & 35 & 16.1286 & 1.80009 & .30427 \\
Control & 35 & 15.9571 & 1.47714 & .24968 \\
\hline
\end{tabular}


Table 2. T-test results of pre-instructed assessments of Experimental and Control group

\begin{tabular}{|c|c|c|c|c|c|c|c|c|c|}
\hline & \multicolumn{2}{|c|}{$\begin{array}{l}\text { Levene's test for } \\
\text { equality } \\
\text { variances }\end{array}$} & \multicolumn{5}{|c|}{ t-test for Equality of Means } & \multirow[b]{2}{*}{$\begin{array}{l}95 \% \\
\text { Interval } \\
\text { Difference }\end{array}$} & \multirow[b]{2}{*}{$\begin{array}{l}\text { Confidence } \\
\text { of the }\end{array}$} \\
\hline & \multirow[t]{2}{*}{$\mathrm{F}$} & \multirow[t]{2}{*}{ Sig. } & \multirow[t]{2}{*}{$\mathrm{t}$} & \multirow[t]{2}{*}{ df } & \multirow[t]{2}{*}{$\begin{array}{l}\text { Sig*. } \\
\text { (2-tailed) }\end{array}$} & \multirow[t]{2}{*}{$\begin{array}{l}\text { Mean } \\
\text { Difference }\end{array}$} & \multirow[t]{2}{*}{$\begin{array}{l}\text { Std. Error } \\
\text { Difference }\end{array}$} & & \\
\hline & & & & & & & & Lower & Upper \\
\hline $\begin{array}{l}\text { Equal } \\
\text { variance } \\
\text { assumed }\end{array}$ & .417 & .521 & .436 & 68 & .665 & .17143 & .39360 & -.61399 & .95685 \\
\hline $\begin{array}{l}\text { Equal } \\
\text { variance } \\
\text { not } \\
\text { assumed }\end{array}$ & & & .436 & 65.504 & .665 & .17143 & .39360 & -.61453 & .95739 \\
\hline
\end{tabular}

According to the results presented above (Table 2), the pre-test scores of the subjects in the experimental and control groups indicated that there was not a statistically or practically significant difference in their mean scores. This trait established an identical basis for the two groups.

\subsection{SILL Questionnaire}

In this study, language learning strategies were identified through Strategy Inventory for Language Learning (SILL) self-report questionnaire (devised by Oxford and Burry-Stock, 1995). The subjects were asked to mark their learning processes and strategies through the retrospective questionnaire of SILL. This instrument was applied in this study to correlate strategy use with proficiency levels. Here is a summary of how subjects from the two main proficiency levels appraised themselves as strategy users.

\subsection{Think-aloud Protocols}

According to the think-aloud protocols, gathered during the ten training sessions, more-proficient listeners approached the task globally, inferring meaning from context, engaging in effective self-questioning, and relating what they had perceived to their world knowledge and personal experience. Their less-proficient counterparts made fewer connections between new information and their own personal experience.

Think-aloud protocols, subjects' oral self-assessment, were conducted after each training session. Goh (2000, p. 59-64) identified listeners' comprehension problems of the listening phases (perception, parsing, and utilization) as below (Table 3):

Table 3. Problem patterns related to the three phases of listening comprehension (Goh, 2000)

\begin{tabular}{lll}
\hline Perception & Parsing & Utilization \\
\hline $\begin{array}{l}\text { Do not recognize words } \\
\text { they know }\end{array}$ & Quickly forget what is heard & $\begin{array}{l}\text { Understand words but } \\
\text { not the intended } \\
\text { message }\end{array}$ \\
$\begin{array}{l}\text { Neglect the next part when } \\
\text { thinking about meaning }\end{array}$ & $\begin{array}{l}\text { Unable to form a metal } \\
\text { representation from words heard }\end{array}$ & $\begin{array}{l}\text { Confused about the key } \\
\text { ideas in the message }\end{array}$ \\
$\begin{array}{l}\text { Cannot chunk streams of } \\
\text { speech }\end{array}$ & $\begin{array}{l}\text { Do not understand subsequent } \\
\text { parts of input because of earlier } \\
\text { problems }\end{array}$ \\
$\begin{array}{l}\text { Miss the beginning of } \\
\text { texts }\end{array}$ & \\
$\begin{array}{l}\text { Concentrate too hard or } \\
\text { unable to concentrate }\end{array}$ & \\
\hline
\end{tabular}


Among the possible problems that Goh encountered in her study, five of them were reported to be more problematic by the experimental groups. In the following figure (Figure 2), these five most common problems that the subjects reported as the most serious ones are illustrated. The figure demonstrates the percentages of experimental subjects for whom these problems seemed to be more challenging.

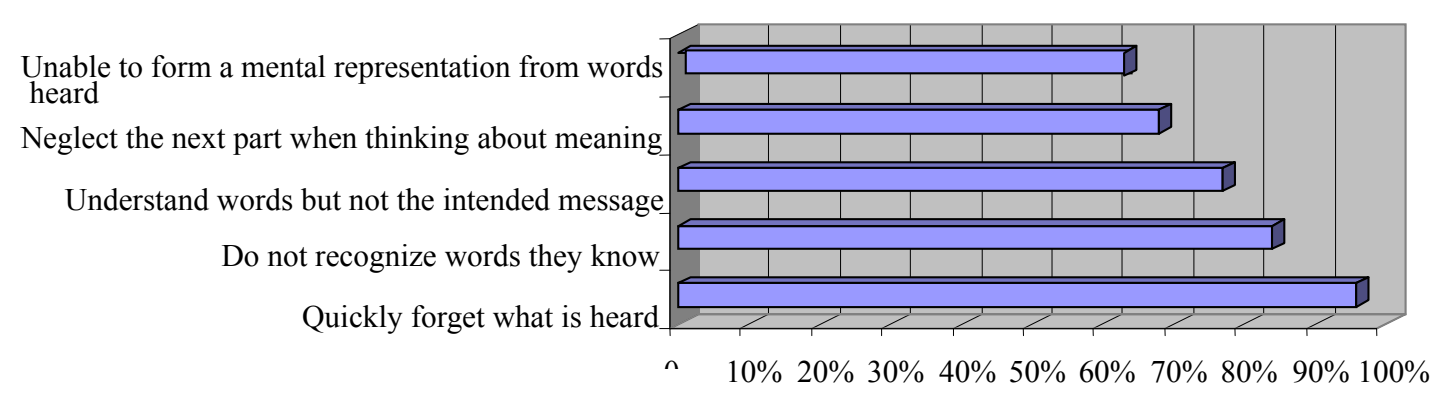

Figure 2. The percentages of five common listening comprehension and recall problems among experimental subjects

\subsection{Comprehension Difficulties}

Concerning the framework proposed by Anderson (1995), we with the help of the lecturer of the training sessions adopted a qualitative analysis of the listeners' think-aloud protocols. Among the possible problems that Goh encountered in her study, five of them were reported to be more problematic by the experimental groups. In the following figure (Figure), these five most common problems that the subjects reported as the most serious ones are illustrated. The figure demonstrates the percentages of experimental subjects for whom these problems seemed to be more challenging.

\subsection{Post-instruction Assessment}

Here, the results were compared with those obtained from the pre-tests to check the possibility of any differences between the two groups. The comparison of the results obtained from the two groups revealed that the instructed group (experimental) performed better than the control group. Table 4 below summarizes the descriptive analysis of the mean post-test scores of the participants; that is $16.44(\mathrm{SD}=1.56)$ for the 'experimental group' and 15.44 $(\mathrm{SD}=2.31)$ for the 'control group'.

Table 4. Descriptive statistics of the post-test scores of experimental and control groups

\begin{tabular}{llllll}
\hline Groups & N & Mean & Std. Deviation & $\begin{array}{l}\text { Std. } \\
\text { Mean }\end{array}$ & Error \\
\hline Experimental & 35 & 16.4429 & 1.56135 & .26392 & \\
Control & 35 & 15.4429 & 2.31609 & .39149 & \\
\hline
\end{tabular}

Table 5. T-test results of post-instructed assessments of experimental and control groups

\begin{tabular}{|c|c|c|c|c|c|c|c|c|c|}
\hline & \multicolumn{2}{|c|}{$\begin{array}{l}\begin{array}{l}\text { Levene's test for } \\
\text { equality } \\
\text { variances }\end{array} \\
\end{array}$} & \multicolumn{7}{|c|}{ t-test for Equality of Means } \\
\hline & $\mathrm{F}$ & Sig. & $\mathrm{t}$ & $\mathrm{df}$ & $\begin{array}{l}\text { Sig*. } \\
\text { (2-tailed) }\end{array}$ & $\begin{array}{l}\text { Mean } \\
\text { Difference }\end{array}$ & $\begin{array}{l}\text { Std. Error } \\
\text { Difference }\end{array}$ & $\begin{array}{l}95 \% \\
\text { Interval } \\
\text { Difference }\end{array}$ & $\begin{array}{l}\text { Confidence } \\
\text { of the } \\
\text { e }\end{array}$ \\
\hline & & & & & & & & Lower & Upper \\
\hline $\begin{array}{l}\text { Equal } \\
\text { variances } \\
\text { assumed }\end{array}$ & 5.268 & .025 & 2.118 & 68 & .038 & 1.00000 & .47214 & .05786 & 1.94214 \\
\hline $\begin{array}{l}\text { Equal } \\
\text { variances not } \\
\text { assumed }\end{array}$ & & & 2.118 & $\begin{array}{l}59.61 \\
3 \\
\end{array}$ & .038 & 1.00000 & .47214 & .05545 & 1.94455 \\
\hline
\end{tabular}

* Mean is significant at 0.05 level $(\mathrm{p}<0.05)$ 
With the benefits of the training sessions, the work of experimental group was satisfactory. Statistically, Table 5 indicates that there was a significant difference in the final output of the two groups $(p<0.05)$.

\section{Discussion}

Following Flavell's framework (1979), Wenden (1999:437) and Victori (1999:539) proposed three aspects for metacognitive knowledge: knowledge of person variables, what learners know about how humans in general learn, as well as what they know about how they as individuals learn; task variables, what learners know about the nature of a task and the demands it might make on their knowledge and skills; and strategy variables, learners' knowledge of different strategies and their appropriate deployment.

\subsection{Identification of Language Learning Strategies}

According to table 1, less-proficient subjects' mean score at listening proficiency test was 46 while more-proficient subjects' was 57. Two weeks later after the listening proficiency test, the subjects sat for the SILL self-report questionnaire, unexpectedly, less-proficient subjects' mean score at the questionnaire was reported to be 15 percent more than more-proficient subjects'. It appeared that less-proficient subjects might have a misconception of what they had actually done in their listening classes, as they thought they were vigorous in applying and practicing various compensating strategies. Surprisingly, more-proficient subjects marked themselves lower than the aforementioned group and maintained that they employed fewer cognitive and metacognitive strategies in the listening tasks.

\subsection{Insights Gained throughout the Training Sessions: Think-aloud Data}

Parallel to Goh's (2000) finding and according to the analysis of the think-aloud data showed, during the first phase, perceptual processing, it turned out that strategies such as "selective attention" and "directed attention" proved to be crucial. More skilled listeners were able to maintain attention or redirect it when distracted, whereas less skilled listeners were easily thrown off when they encountered anything unknown. In this phase, subjects were required to focus on the text to segment the phonemes from the speech stream. Therefore, listeners' wrong grasp of sounds would interfere with comprehension if they did not monitor their attention carefully and concurrently.

During parsing, the second phase, grouping and inferencing proved to be crucial strategies. More-proficient listeners processed larger chunks and inferred the unknown from the context using a top-down approach. When this failed, they attended to individual words. Less-proficient listeners tended to segment what they had heard on a word-by-word basis, using almost exclusively a bottom-up approach. Field (2004:64) asserts that the terms 'bottom up' and 'top down' refer not to particular levels of processing but to directions of processing. In a 'bottom-up' process, small (lower level) units are progressively reshaped into larger ones; in a top-down process, larger units exercise an influence over the way in which smaller ones are perceived.

Finally, as Anderson suggested (1995) and as Goh (2000:59) confirmed, during the last phase, utilization, "listeners made use of prior knowledge to assist comprehension and recall". Elaboration is what subjects knew about the topic and inferencing is the ability to predict possibilities (Chamot and Kupper, 1989:20). Thus, elaboration seems to be the dominant strategy, and the degree to which listeners are able to use this strategy determines their effectiveness as listeners.

\subsection{Listening Comprehension Difficulties}

As it follows, the five most problematic stages of listening which were identified throughout a whole semester are explained and elucidated through exact evidence from the subjects' think-aloud protocols. The reasons some subjects cited for these problems are also mentioned.

\subsubsection{Quickly Forget What Is Heard}

According to the Figure 2, nearly all the subjects, 94 percent, reported that they could not remember certain words and phrases they had just heard or even they had missed the content. One of the most common complaints was that although they could understand what was said when they heard the passage, they would forget it as soon as they began listening to another part of the message.

\section{When I listen to a new text, I forget what I have understood formerly. (H.M.) (Note 1)}

2. When I listen in English, I can understand most of words, but I forget the precedent sentences after listening to the present sentence. (N.B.)

The subjects recognized words in the aural text and had apparently understood what they heard, but they soon forgot the contents. A possible cause is the limited capacity of the listeners' short-term memory. However, two 
factors, as Nagle and Sanders (1986:15) believe, can also impede the processing of new information: trace decay (fading of the sensory input) and interference from newly arriving input. To overcome these impeding factors, Nagle and Sanders (1986:15-16) believe that associative links between words may strengthen an item in short-term memory, besides, Robinson (1995:322) asserts that input decoding will become manageable if the detection of input is followed by rehearsal in short-term memory.

Overlap among the three comprehension phases was evident from some subjects' verbal reports. There was some indication that the subjects experienced this problem most when the part they had just parsed was followed by input with unfamiliar elements, such as new concepts or vocabulary. H.M (comment 1) seemed to suggest this. Having to process more demanding input had most probably caused a cognitive overload. This would have resulted in little or no spare processing capacity to form meaningful associations with existing knowledge in long-term memory. N.B. (comment 2) suggests that the listener had successfully perceived and parsed the input. However, before he could utilize the interpretation (store it in long-term memory for later retrieval), it was displaced by new input occupying the limited-capacity short-term memory. As a result, he could no longer recall the words or the meaning of what he had parsed.

\subsubsection{Do Not Recognize Words They Know}

The second most common problem the subjects faced during listening was related to a fundamental aspect of comprehension-perceptual processing. As it was depicted in Figure 2, 83 percent of subjects said that although some words sounded familiar, they were unable to recall their meanings immediately. Consequently, they were unable to process the message using those words. Here are two reports highlighting this:

3. When I listen to English news, some words sound familiar but I cannot remember their meanings. (N.H.)

4. For example, I know the word "optimum", and if I read this, I can easily understand but I couldn't get it during the listening task. (F.S.)

Many subjects, such as N.H. and F.S. (comments $3 \& 4$ above), remarked that they had to learn to speed up their reaction to the words they heard. A possible reason for this slow recognition is that the subjects could not match the sounds they heard with any script in their long-term memory. It is likely that for some of them, "sound-to-script relationships have not been fully automatized" (Goh, 2000:61). Therefore, although they knew certain words by sight, they could not recognize them by sound. Put another way, "their listening vocabulary was underdeveloped" (Ibid.). Their ability to understand spoken words was greatly handicapped because they had not stored the sounds of lexical items efficiently in long-term memory. This underdeveloped listening vocabulary can be directly related to the way the subjects learnt new words. Many of them said they learnt by memorizing the spelling of words and often neglected to remember how the words sounded.

Another possible explanation for this problem is that word-referent relationships might not be automatized (Field, 2003:16). Concurrently, Garrod \& Pickering (1999:88) believe in recency effect and suggest that spreading activation may also be the explanation for an effect known as priming. Priming occurs when a word with a similar semantic representation is presented before the target.

\subsubsection{Understand Words But Not the Intended Message}

According to Figure 2, almost $76 \%$ of the subjects said that they were unable to get the full meaning of the message even though they had understood the word-by-word meaning of the clauses. This is a utilization problem because it is related to the listeners' ability to make useful elaborating inferences or act on the intended meaning of the message (Goh, 2000:62).

5. Sometimes I don't think when I'm listening, I just find the meaning, not the contextualized meaning. (N.R.)

Most subjects did not explain why they could not get the intended meaning from what they heard, though in some think-aloud protocol the reason was given, as Z.A. and N.R. (comment $5 \&$ 6). Sometimes, the reason could be inferred from the verbal report, as with the following comment by G.B. (comment 6):

6. I listened to the text. A man talked some genetic factors affecting the amount of rice yield. I can understand most of the words, but I can't join them together and understand whole sentences meaning. (G.B.)

This subject did not have sufficient background knowledge, or the relevant schema, for the text he was listening to. His lack of prior knowledge about genetics had limited his top-down processing of the text. Carrell \& Eisterhold (1983:562) believe that through membership in a culture, an individual has privileged information which is represented in a rich system of schemata. Therefore, in such a case of foreign language learning context, 
there was a mismatch between the background knowledge presupposed by the text and the background knowledge possessed by the subjects.

Moreover, inferencing is a process essential to comprehension (Eysenck and Keane, 1995:104) and a crucial mental activity during utilization (Anderson, 1995:213). In the absence of a relevant schema, G.B. (comment6) was unable to make appropriate elaborating inferences. Besides limitations of content knowledge, problems during utilization may also arise from the listener's lack of communicative competence (Ali, 2007:163). The listener might be able to make literal sense of an utterance at the parsing phase, yet still not understand the illocutionary force the utterance might have, as the following report shows (Wenden, 1999:438), as reported by M.H. (comment 7).

7. I think culture is the key element in language. Sometimes I can catch the whole sentence. But I can't understand the true meaning of the words. (M.H.)

\subsubsection{Neglect the Next Part When Thinking about Meaning}

The fourth most common problem cited by 66 percent of the experimental subjects was missing the next part of a text when they stopped to think about unfamiliar words or the interpretation of a segment of text (Figure 2). As Goh (2000:63) explains, this is an attention problem which directly affects the amount of acoustic input that can be perceived and processed. The following protocol K.E. (comment 8) shows this problem:

8. When I listen clearly to the first sentence and think about its meaning, the second has come, so what can I do now? (K.E.)

These reports not only illustrate a common listening problem, they once again show overlapping of the three phases of comprehension (perception, parsing, and utilization). Twenty-three out of thirty-five experimental subjects were unable to process the information fast enough; therefore, they experienced several problems simultaneously: they could not understand some words and so tried to search for the meaning. This had to be done under the constraints of a limited short-term memory, which was further limited by the demands of processing a language in which they were not completely proficient (Field, 2004). The decreasing cognitive processing capacity became even more severely overloaded when they had to keep up with the new input. Goh (2000, p. 64) explains that this problem could have caused the subjects "to be caught in a vicious circle of perception and parsing, with few opportunities to utilize mental representations they tentatively formed".

\subsubsection{Unable to Form a Mental Representation from Words Heard}

The last of the five common problems occurs at the parsing phase. 61 percent of subjects reported that they failed to derive a reasonable mental representation of the input by connecting the words they heard (see Figure 2 above).

9. When I was listening, I could catch most words. But I could not put all the words into a full sentence to get a full idea. (R.I.)

One likely reason for this problem is that many of the words the subjects managed to hear were not key or content words, but merely words the subjects were familiar with and could recognize instantly (Graham, 2006, p. 168). M.K. (comment 10) demonstrated her insight into this problem when she said:

10. I mean, for example, you say I'm going to do something. Catch the first part "I'm going to do" but I usually miss the content word that comes after. (M.K.)

Tomlin and Villa (1994, p. 196) realize that foreign language learners do not yet know the specific mapping relations holding between mental representation and syntactic information, and it is precisely these that listeners must struggle to incorporate into their developing interlanguage grammar. They (Ibid.) believe:

1. The learner must discern that there is a relationship between these two levels of grammatical form and mental representation.

2. The learner must send those observations off for further processing (hypothesis formation and testing).

In line with the above findings, during the training sessions, the researcher with the help of the lecturer provided the subjects with numerous examples which exemplified how the subjects' knowledge of grammar (i.e., types of sentences and questions, different roles of subject and object, and verbal transitivity) could fill their comprehension gaps which impeded the formation of an appropriate mental representation.

\section{Conclusion}

This study has provided an introspective understanding of the subjects' language processing system. The findings of the study can serve as a useful cue to the causes of ineffective low-level processing and provide insights to 
solve some of the problems of parsing. Results of this study show that: (a) a higher level of strategy awareness correlates positively with language development, and (b) students who received explicit instruction outperformed those exposed to implicit instruction. While the conducted study shows that explicit instruction is favored over implicit instruction when the instructional period is short, it does not rule out that longer instructional treatments might produce different results, especially in light of Ellis's (1993) assertion that learning under implicit conditions is generally slow and requires more input to become effective.

\section{Acknowledgements}

We would like to thank Dr. Shushtari, first, for her support and concern, and second, for her sincere assistance in gathering data phase of this paper. We also gratefully acknowledge Dr. Hayati for his warm company along this study.

\section{References}

Ali, G. (2007). Assessment of metacognitive knowledge among science students, a case study of two bilingual and two NNS students. System, 35(2), 148-168.

Anderson, J. R. (1995). Cognitive psychology and its implications. New York: Freeman.

Arnold, J. (2000). Seeing through listening comprehension exam anxiety. TESOL Quarterly, 34(4), 777-786.

Brown, H. D. (2000). Principles of Language Learning and Teaching. New York: Longman.

Buck, G. (2001). Assessing listening. Cambridge: Cambridge University Press.

Call, E. (1985). Auditory short term memory, listening comprehension and the Input Hypothesis. TESOL Quarterly, 19(4), 765-781.

Carrell, P. L., \& Eisterhold, J. C. (1983). Schema theory and ESL reading pedagogy. TESOL Quarterly, 17(4), 553-573.

Carroll, D. W. (1994). Psychology of language. (Second edition). Pacific Grove, California: Brooks/Cole Publishing Company.

Chamot, A. U., \& Kupper, L. (1989). Learning strategies in foreign language instruction. Foreign Language Annals, 22(1), 13-24.

Chamot, A. U., S. Barnhardt, P. B. El-Dinary, \& J. Robbins. (1999). The Learning Strategies Handbook. White Plains: Addison Wesley Longman.

Chun, D. M., \& Payne, J. S. (2004). What makes students click: working memory and look-up behavior. System, 32(4), 481-503.

Cohen, A. (1998). Strategies in learning and using a second language. London: Longman.

Doughty, C., \& Williams, J. (1998). Focus on form in classroom second language acquisition. Cambridge: Cambridge University Press.

Dreyer, C., \& Nel, C. (2003). Teaching reading strategies and reading comprehension within a technology-enhanced learning environment. System, 31(3), 349-365.

Ellis, R. (1985). Understanding Second Language Acquisition. Oxford: Oxford University Press.

Ellis, N. (1993). Rules and instances in foreign language learning: Interactions of explicit and implicit knowledge. European Journal of Cognitive Psychology, 5(3), 289-318. http://dx.doi.org/10.1080/09541449308520120

Eysenck, M. W., \& Keane, M. T. (1995). Cognitive psychology. Sussex: Psychology Press.

Field, J. (1998). Skills and strategies: towards a new methodology for listening. ELT Journal, 52(2), 110-118.

Field, J. (2000). 'Not waving but drowning': a reply to Tony Ridgeway. ELT Journal, 54(2), 186-195.

Field, J. (2003). Promoting perception: lexical segmentation in L2 listening. ELT Journal, 57(4), 325-333.

Field, J. (2004). An insight into listeners' problems: too much bottom-up or too much top-down? System, 32(3), 363-377.

Flavell, J. H. (1979). Metacognition and cognitive monitoring: a new area of cognitive developmental inquiry. American Psychologist, 34(10), 906-911.

Garrod, S., \& Pickering, M. (1999). Language processing. Sussex: Psychology Press. 
Goh, C. C. M. (2000). A cognitive perspective on language learners' listening comprehension problems. System, 28(1), 55-75.

Graham, S. (2006). Listening comprehension: the listeners' perspective. System, 34(2), 165-182.

Larsen-Freeman, D. (2001). Individual cognitive/affective learner contributions and differential success in second language acquisition. In M. P. Breen (ed.), Learner Contributions to Language Learning: new directions in research (pp. 12-24). London: Longman.

Leow, R. P. (1997). Attention, awareness, and foreign language behavior. Language Learning, 47(3), 467-505.

Lynch, T. (1998). Theoretical perspectives on listening. Annual Review of Applied Linguistics, 18, 3-19. http://dx.doi.org/10.1017/S0267190500003457

McLaughlin, B., Rossman, T., \& McLeod, B. (1983). Second language learning: an information-processing perspective. Language Learning, 33(2), 135-158.

Nagle, S. J., \& Standers, S. L. (1986). Comprehension theory and second language pedagogy. TESOL Quarterly, 20(1), 9-26.

Oxford, R. L., \& Burry-Stock, J. A. (1995). Assessing the use of language learning strategies worldwide with the ESL/EFL version of the Strategy Inventory for Language Learning (SILL). System, 23(1), 1-23.

Radwan, A. A. (2005). The effectiveness of explicit attention to form in language learning. System, 33(1), 69-87.

Robinson, P. (1995). Attention, memory, and the "noticing" hypothesis. Language Learning, 45(2), 283-331.

Shiffrin, R. M., \& Schneider, W. (1977). Controlled and automatic information processing: perceptual learning, automatic attending, and a general theory. Psychological Review, 84(2), 127-190.

Tomlin, R. S., \& Villa, V. (1994). Attention in cognitive science and second language acquisition. Studies in Second Language Acquisition, 16(2), 183-203. http://dx.doi.org/10.1017/S0272263100012870

Victori, M. (1999). An analysis of writing knowledge in EFL composing: a case study of two effective and two less effective writers. System, 27(4), 537-555.

Wenden, A. (1999). An introduction to 'Metacognitive knowledge and beliefs in language learning': beyond the basics. System, 27(4), 435-441.

\section{Note}

Note 1 . The numbered comments describe each problem reported by our subjects whose names are abbreviated. 